\title{
$\mathbf{R}$

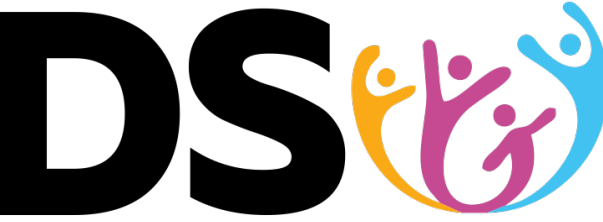

Revista Desenvolvimento Social

\section{MISÉRIA, DIALÉTICA E LIBERTAÇÃO}

\author{
David Pavón Cuéllar ${ }^{1}$ \\ lan Parker $^{2}$ \\ Tradução de Paulo Beer ${ }^{3}$
}

Recebido em: 06/11/2020

Aprovado em: 22/12/2020

Resumo: Este artigo argumenta que Freud não aceitou a esfera da "psicologia" como algo dado, que poderia ser conhecido objetivamente. Tampouco ele a via como algo unitário que seria sempre o mesmo e em qualquer pessoa. Ao invés disso, ofereceu ideias valiosas sobre a natureza humana da miséria enquanto algo histórico, sobre o processo dialético através do qual podemos entender a miséria como algo condensado em sintomas, e sobre a relação entre compreensão e libertação. Nós argumentamos que a psicanálise precisa ser recriada por nós enquanto uma ferramenta de trabalho radical sobre a subjetividade para derrubar as condições existentes. Argumentamos em favor de uma compreensão dialética da psicanálise como uma ferramenta e um resultado; essa ferramenta é o resultado das elaborações teóricas de Freud e seus seguidores, que nos permitiram usá-la para um trabalho radical na clínica e em movimentos de libertação. Ela torna possível uma "subjetividade revolucionária", um "sujeito revolucionário".

Palavras-chave: Psicanálise. Miséria. Revolução.

\section{MISERY, DIALECTICS AND LIBERATION}

\begin{abstract}
This article argues that Freud did not accept the sphere of 'psychology' as something given that could be known objectively. Nor did he see it as something unitary that would be the same always and in any person. Instead, he provided valuable insights into the human nature of misery as something historical, into the dialectical process through which we can understand misery as something condensed in symptoms, and into the relationship between understanding and liberation. We argue that psychoanalysis needs to be recreated by us as a tool of radical work on subjectivity in order to overthrow of existing conditions. We argue for a dialectical understanding of psychoanalysis as a tool and result; this tool is the result of the theoretical elaborations of Freud and followers, who enabled us to use it for radical work in

\footnotetext{
${ }^{1}$ Professor de psicologia na Universidad de San Nicolás de Hidalgo em Morelia, Mexico. ORCID: 00000003-1610-6531.

2 Pesquisador-professor honorário na Universidade de Manchester, Reino Unido. ORCID: 0000-00015950-464X.

${ }^{3}$ Psicanalista, coordenador do Núcleo de Estudos e Trabalhos Terapêuticos (NETT). ORCID: 0000-00019702-4209.
} 
the clinic and with liberation movements. It makes possible 'revolutionary subjectivity', a 'revolutionary subject'.

Keywords: Psychoanalysis. Misery. Revolution.

\section{MISERIA, DIALÉCTICA Y LIBERACIÓN}

Resumen: El presente artículo sostiene que Freud no aceptó la esfera de la "psicología" como algo dado que pudiera ser conocido objetivamente. Tampoco la vio como algo unitario que sería lo mismo siempre y en cualquier persona. En cambio, brindó valiosos conocimientos sobre la naturaleza humana de la miseria como algo histórico, sobre el proceso dialéctico a través del cual podemos entender la miseria como algo condensado en síntomas y sobre la relación entre comprensión y liberación. Sostenemos que el psicoanálisis debe ser recreado por nosotros como una herramienta de trabajo radical sobre la subjetividad para derrocar las condiciones existentes. Abogamos por una comprensión dialéctica del psicoanálisis como herramienta y como resultado; esta herramienta es el resultado de las elaboraciones teóricas de Freud y de sus seguidores, quienes nos permitieron utilizarla para un trabajo radical en la clínica y con los movimientos de liberación. La misma comprensión dialéctica hace posible que haya una "subjetividad revolucionaria", un "sujeto revolucionario".

Palabras-clave: Psicoanalisis. Miseria. Revolución.

\section{INTRODUÇÃO}

Todos sob pressão, sejam eles trabalhadores na fábrica, no escritório, na loja, nos campos, nas ruas ou na casa, precisam de apoio prático e emocional em algum momento de suas vidas, e ainda mais ativistas lutando para mudar o mundo. Ativismo em movimentos de libertação usualmente é um teste duro para pessoas que precisam romper com seus passados, deixar os papéis que lhes foram atribuídos, confrontar seus ambientes, questionar a eles mesmos, separarem a si mesmos de suas identidades anteriores e se sacudirem daquilo que os segura em seus lugares, ou abrir mão dos privilégios que os tentam a se agarrarem no que já têm.

Às vezes, nossos privilégios, no caso dos super-ricos, os 1\%, são enormes, mas frequentemente esses privilégios que nos afastam um dos outros são supreendentemente pequenos. É surpreendente que, sendo tão insignificantes, possam ser tão importantes para nós. Sua pegada é material, mas também "psicológica"; uma coisa que a psicanálise compreende e pode transformar.

Nós devemos nos desprender de nossas correntes psicológicas para podermos nos dar conta de que somos diferentes tipos de trabalhadores. Seja quão grande forem as diferenças entre nós, existe o trabalho que fazemos para viver e ao viver, e 
devemos reconhecer isso para unir forças e ganhar o mundo. Continuaremos a perder o mundo, até perdê-lo completamente, enquanto permanecermos presos dentro daquilo que fomos forçados a ser.

Cada um precisa libertar não somente a si mesmo, mas de si mesmo. Isso causa rupturas internas, até mesmo formas de trauma que podem ser consideradas, estudadas e tratadas. Elas não podem ser completamente resolvidas, mas compreendidas, compreendidas e transformadas pela teoria e pela prática psicanalíticas do médico vienense Sigmund Freud no final do século XIX, e então refinadas e desenvolvidas por seus discípulos e seguidores nos últimos cem anos. A história da herança freudiana é a de um tratamento único e sem paralelos das rupturas internas da subjetividade moderna. Também é a história de uma relação complexa, ambivalente e contraditória com seu objetivo final, o da libertação. Essa história foi feita de avanços, desvios, rodeios e reveses. Desde o início, Freud era um filho de seu tempo, mergulhado numa ideologia sexista e racista - e em sua própria formação psiquiátrica - , mas ele rompeu com ideias dominantes sobre psicologia e natureza humana para abrir caminho a uma "psicologia crítica" potencialmente progressista.

Freud se relacionava criticamente com a esfera psicológica. Ele não a aceitava como algo dado, real e inteiramente manifesto, que podia ser conhecido objetivamente. Tampouco ele a via como algo unitário que seria sempre o mesmo e em qualquer pessoa. Isso o permitiu ter insights valiosos sobre a natureza humana da miséria como algo histórico, sobre o processo dialético através do qual podemos compreender essa miséria como algo condensado em sintomas, e sobre a relação entre compreensão e libertação.

\section{SINTOMAS DA MISÉRIA COMO UM FENÔMENO HISTÓRICO}

O que Freud fez foi compreender aquilo que parecia ser sintomas médicos, que prendiam as pessoas psicologicamente, como "sintomas" de um tipo muito diferente. Esses "sintomas" não podiam mais ser explicados ou tratados pela medicina, mas demandavam outros meios teóricos e práticos. A psicanálise foi desenvolvida por Freud, mesmo que ele tenha sido treinado como um "doutor da mente" tradicional, de tal maneira como se para romper completamente com a psiquiatria médica e com os 
tipos de psicologia que ainda tratam o sofrimento dentro de um modelo médico bastante mecanicista. Como iremos ver, diferentemente dos sintomas da medicina, os "sintomas" psicanalíticos não são simples sinais visíveis. Eles são mais como palavras que demandam serem escutadas, que falam, elas falam de angústia e resistência, e abrem possibilidades de mudança.

O mundo pode ser transformado ao se tratar os sintomas da forma como a psicanálise o faz, escutando-os, levando eles a sério e agindo de acordo. Ações políticas transformativas, subversivas e potencialmente revolucionárias podem emergir do discurso sintomático de nosso sofrimento, daquilo que não pode continuar, daquilo que deve mudar. É por isso que sintomas devem nos interessar nesse manifesto.

Aqui estamos especialmente interessados na ligação psicanalítica entre discurso e ação, ação política, que tenta superar as mais fundamentais causas sociais do sofrimento. A pressão e as rupturas internas que sofremos falam da natureza particular do sofrimento nessa desgraçada sociedade que queremos tanto mudar, e a psicanálise é uma aliada potencialmente potente nesse processo.

Nossa tarefa é conectar a luta social com o tipo de luta interna inevitável descrita pela teoria psicanalítica. A proposta prática não é a finalidade terapêutica de nos pacificar, reconciliando-nos internamente com nós mesmos e com a sociedade, mas a finalidade política radical de ir à raiz de nossa batalha interna. Isso faz a psicanálise que nos interessa aqui divergir significativamente de qualquer terapia individual readaptativa psicanaliticamente inspirada.

A psicanálise, uma teoria e prática de nossas "vidas mentais internas", divididas e rasgadas, esteve frequentemente aliada ao poder, mas ela realmente pode fornecer uma crítica política e clínica da miséria. Não é algo a se temer. Ela não foi projetada para nos subjugar pela adaptação de nossa existência à ordem estabelecida, por nos fazer desconfiar de nossos ideais transformativos, por nos distanciar de nossas lutas coletivas, por nos prender dentro de nossas mentes individuais ou por superar nossa resistência mais íntima contra dominação.

O que Freud nos deixou não é um instrumento de isolamento, resignação e sujeição. É verdade que a psicanálise funciona assim às vezes, como todas as aproximações a nossas vidas mentais já funcionaram. Isso não é surpreendente numa 
sociedade de classes, que divide curadores profissionais do resto das pessoas, thes conferindo uma função precisa ligada ao poder.

A psicanálise também nos ensina que qualquer profissional, seja um médico, um psiquiatra, ou um psicólogo ou psicoterapeuta não médico, também é dividido, rasgado por suas vidas conflituosas. Que muitos se esforçam por uma carreira de sucesso, mas eles também lembram, às vezes, o que os levou a se formarem para cuidar de outros. Todos nós vivemos tensões de um modo ou de outro, as administramos, e usualmente as recobrimos. A questão principal é o que nós fazemos com esses conflitos e contradições, se vamos fazê-los trabalhar por nós ao invés de contra nós.

Embora tenha sido usada de maneiras reacionárias, a psicanálise não é, ela mesma, reacionária. Ela não é, necessariamente, um instrumento de dominação. Ao contrário, ela pode ser uma arma contra o poder. Ela pode mostrar como nossa própria psicologia é colonizada pela realidade, essa miserável realidade da vida sob o capitalismo, e como nós podemos falar e agir contra essa psicologia individualizada enquanto nos engajamos em nossa própria libertação.

Nós somos mais do que aquilo que nos é dito, pelos profissionais psi, que nossa "psicologia" é. Não estamos condenados a nos calar dentro de nossa individualidade ou a suportar a realidade, ou sua miséria, ou o sistema capitalista. Nos é dito que não podemos mudar as coisas, mas nós podemos, e precisamos de uma abordagem que seja fundada nessa possibilidade de mudança.

\section{Adaptação}

A psicanálise - que é uma abordagem psicológica crítica para o sofrimento e um tratamento radical inventado no começo do século $X X$ - já foi, uma vez, uma aliada explícita da esquerda. A maioria dos psicanalistas eram membros ou apoiadores dos movimentos comunistas e socialistas antes que suas próprias organizações fossem destruídas pelo fascismo na Europa, e antes que eles fugissem para diferentes partes do mundo. Esses psicanalistas tinham um compromisso de mudar o mundo porque eles podiam ver, e ouvir de seus pacientes, a miséria que existia nele. 
Os "sintomas" escutados pelos primeiros psicanalistas não eram meras indicações de problemas médicos orgânicos. Eles eram sinais de conflitos, conflitos que não eram somente pessoais, mas ideológicos, políticos e históricos. Os sintomas eram, eles mesmos, conflitos condensados e expressos numa tessitura sintomática. Esse é o tipo de sintoma que a psicanálise sabe escutar.

Com o passar do tempo, como veremos agora, muitos psicanalistas perderam a arte da escuta. A escuta deles, algumas vezes, cedeu lugar para uma mirada objetificante e classificadora. A psicanálise se tornou, gradualmente, uma especialidade médica ou psicológica. Sua prática virou uma simples técnica, supostamente científica e deliberadamente despolitizada.

Mesmo os primeiros psicanalistas, sob condições hostis em seus novos países anfitriões depois que fugiram, tiveram que renunciar à militância política e se proteger contra a perseguição anticomunista dos países ocidentais durante a Segunda Guerra e depois na Guerra Fria. Eles fingiam ser apolíticos e, então, adaptados a suas novas realidades, e eles despolitizaram e adaptaram a psicanálise, transformando-a, ela mesma, num tratamento adaptativo. Essa adaptação é crucial para a história da psicanálise como um modo de tratamento na clínica e para o lugar que ela ocupa na cultura popular.

Os tipos de conflito que os sintomas falavam sobre eram agora vistos como coisas a serem resolvidas num nível pessoal, e a política era deixada de fora da clínica. Então, quando as ideias psicanalíticas eram erroneamente "aplicadas" à sociedade, era esse tipo reduzido de psicanálise adaptativa que era usada como um modelo para como a sociedade funcionava e ao que qualquer outra sociedade poderia parecer.

Durante esses tempos severos, e eles eram severos tanto para os psicanalistas como para aqueles que eles tratavam, era quase como se a história radical da teoria e da prática inovadora de Freud tivesse morrido. Alguns clínicos lutavam para mantê-la acontecendo, e alguns teóricos sociais tentaram usá-la para alcançar as condições históricas subjacentes que a levaram a esquecer seu próprio passado. Quase todos eles compreendiam muito bem, de um jeito ou de outro, que a psicanálise tinha capitulado, que ela tinha permitido a si mesma ser recuperada e domesticada, adaptando e se tornando adaptativa. Agora nós precisamos libertar a psicanálise de 
sua ligação histórica com a adaptação, levar a sério seu âmago histórico autenticamente radical, e fazê-la viver de novo.

Se devemos rejeitar a psicanálise adaptativa, é porque essa versão conservadora dominante da psicanálise renuncia a seu potencial transformativo. Ela não nos permite transformar a nós mesmos, mas somente nos adaptar e, então, aceitar e perpetuar a realidade como ela é, mesmo tão opressora, exploradora ou alienante como ela pode ser. Assim, embora o capitalismo seja injusto e intolerável, nós nos adaptamos a ele como se fosse nosso ambiente natural, como se não fosse histórico e, portanto, superável.

O problema da psicanálise adaptativa não é só que ela naturaliza o histórico, mas que ela nos faz ver o mundo como um ambiente diferente de cada um de nós. Isso nos impede de reconhecer que somos parte do mundo, que somos o mundo e podemos transformá-lo ao nos transformar, mas também transformar a nós mesmos ao transformar o mundo. Pela mesma razão, ao conceber o mundo como um ambiente, nós confortavelmente dissimulamos sua constituição enquanto uma trama ou estrutura ecológica em que somos todos responsáveis pelos outros, o que pode ser facilmente experienciado tanto através de psicanálise não adaptativa como de formas emancipatórias de ação coletiva.

Todo movimento de libertação aprende, em algum momento, que existe uma diferença crucial entre "ambiente" e "ecologia", e essa diferença se explicita quando eles conectam suas lutas com uma compreensão ecossocialista do mundo. Falar de "ambiente" é falar do mundo como algo separado de nós, ao que nós precisamos aprender a nos ajustar ou tentar dominar, enquanto "ecologia" se refere à interconexão íntima entre nós e o mundo. Nossas vidas estão ligadas nas redes de solidariedade e consciência política de tal maneira ecológica que nós sentimos a dor dos outros em dificuldades, e sabemos que só vamos piorar o mundo se tentarmos dominar e explorar os outros, sejam eles colegas humanos ou outros seres conscientes. Essa consciência ecológica de nossa ligação com os outros está no coração da psicanálise.

Como concebido pela psicanálise, os indivíduos não estão realmente sozinhos, isolados e separados um dos outros. Nós somos parte das vidas dos outros e nossas ações e palavras podem ter consequências fatais para eles. De alguma maneira, 
sabemos que somos tão responsáveis por eles quanto por nós mesmos. Nossas ligações não são somente "externas". Os outros não estão somente "fora", ao nosso redor, mas também "dentro", em cada um de nós, naquilo que pensamos, dizemos e fazemos. Nos nossos gestos há traços dos outros, assim como em nossas palavras e ideias também há ecos de outras vozes. Relações passadas com os outros não somente reaparecem nas relações presentes, mas também estão amarradas em cada um de nós e nos fazem quem somos. A constituição do indivíduo é social e cultural, mas também histórica, o que o faz se transformar incessantemente.

Assim como as condições de exploração, opressão e alienação que enfrentamos são construídas, historicamente construídas - e então podem ser extinguidas por nós-, também nossas formas peculiarmente alienadas de psicologia são produtos da história e podem ser modificados. Isso é, apesar das reivindicações da maioria dos psiquiatras, psicólogos e psicoterapeutas de estarem trabalhando sobre propriedades universais imutáveis da vida mental. O trabalho deles é, na verdade, sobre fatores extremamente variáveis determinados pela cultura, pelo momento histórico, pelas relações sociais existentes.

Psicanalistas conservadores adaptativos, junto com a maior parte dos profissionais psis, tornam a natureza histórica da existência humana, em contínua mudança, em algo fixo. Isso é ainda mais curioso e reacionário na sociedade atual, em que tudo está mudando tão rápido, onde, de fato, é como se tudo que é sólido derretesse no ar. Somos, nós mesmos, forçados a ser flexíveis e a aprender a existir em cada momento de um jeito diferente, mas os profissionais psis fixam nossa existência num lugar, como se fosse um objeto conforme eles estudam e tentam tratá-la, assim traindo o que é mais radical e transformativo sobre a existência humana enquanto tal. A imagem deles da natureza humana é de que ela não seria muito mais do que uma máquina complicada ou um animal bruto, esse mecanismo instintual puro, o qual só existiu na imaginação de seres humanos para que eles se sentissem superiores quando comparados com ele. Quem teria pensado que esses mesmos seres humanos estariam finalmente confusos com suas representações degradantes do animal? É como se a velha degradação do animal em contraste com o ser humano tenha servido para preparar para a degradação atual do ser humano na psicologia e em outras profissões psi, incluindo a psicanálise conservadora. 
A psicanálise radical, em contraste, nos ensina que está na natureza dos seres humanos refletir sobre suas condições sociais e, a todos nós, continuamente tentar transformar essas condições e a nós mesmos. Nós tentamos mudar e falhamos, e é a psicanálise radical, junto à prática política, que nos mostras por que falhamos, e como nós estamos presos pelos ideais dominantes de sociedade e pela biografia única de cada pessoa. Nós não podemos esperar que desapareçam as condições históricas que nos tornam quem somos, tampouco podemos esperar que desapareçam os obstáculos internos que nos vinculam a nossa opressão, que nos incitam a desejar opressão ao mesmo tempo que nós nos ressentimos e tentamos fugir disso. Não podemos sequer sermos capazes de nos libertar de nosso desejo por opressão, mas podemos conhecêlo, discerni-lo quando ele intervém, e esse conhecimento pode ser o primeiro passo para nossa libertação.

Desejar opressão é uma coisa bastante peculiar, um dos dolorosos paradoxos da subjetividade. A coisa mais fácil a fazer é fingir que tal paradoxo não existe, mas cedo ou tarde nós iremos tropeçar nele e ele pode comprometer nossa luta por libertação. Talvez no final, respondendo ao nosso desejo, nós iremos criar novas formas de repressão para substituir aquelas das quais nos libertamos. Para evitar isso, precisamos levar a sério o que nos faz voltar aonde começamos, o que nos faz parar ou nos puxa de volta se estamos seguindo em frente. Devemos levar tudo isso a sério, não para culpar a vítima, mas para entender a natureza contraditória de cada um de nós enquanto seres humanos nesse mundo desgraçado.

\section{História}

A psicanálise, como o marxismo e outras teorias sobre poder e libertação, emergiu num período histórico específico para conceitualizar, entender e resolver uma série de problemas historicamente criados. Fora do contexto histórico dos dois últimos séculos, a psicanálise não faria todo o sentido que faz para nós. O mesmo aconteceria com o marxismo, se o levássemos para outra era.

É difícil imaginar, por exemplo, o que escravos querendo fugir de seus governantes na Roma Antiga teriam feito com análises marxistas da "mais-valia" - a quantia escondida que o capitalista toma do trabalhador - , ou de tentativas de 
construção de partidos revolucionários e associações internacionais. O proletariado não existia no tempo de Espártaco. Libertar-se da escravidão não era o mesmo que se libertar da exploração do trabalho livre. É por isso que o marxismo só começou a ser útil quando o próprio capitalismo veio ao mundo como o modo de produção dominante. Da mesma maneira, o desenvolvimento de estados coloniais e do imperialismo foi necessário para que existissem movimentos de libertação anticoloniais e anti-imperialistas. Cada movimento político surgiu para combater condições de exploração ou de opressão particulares.

No caso da psicanálise, os "sintomas" do sofrimento que ela foi inventada para entender e tratar são bastante específicos da sociedade moderna. Esses sintomas são tão históricos quanto a representação freudiana da psique. O que é "inconsciente" é bastante amarrado com a forma de alienação peculiar que sofremos na modernidade capitalista.

A alienação, no capitalismo, produz conflitos "internos" que podem ser invisíveis dessa maneira, mas que são conhecidos por seus efeitos, por aquilo que causam ou motivam nas pessoas, como seus sofrimentos inexplicáveis, o desarranjo de suas vidas, suas decisões absurdas ou ações erráticas, às vezes destrutivas ou autodestrutivas. Tudo isso é evidente na experiência de trabalho atual. As pessoas estão presas em suas vidas de trabalhadores de tal maneira que repetem os mesmos tipos de tarefas, e suas experiências de vida são então estruturadas de um jeito repetitivo particular que está fora de seus controles. Os trabalhadores, todo mundo que trabalha hoje, são levados a fazer isso por imperativos econômicos, e então o que é ser sujeito a uma "pulsão" de trabalhar e sobreviver é atrelado ao capitalismo. A dominação capitalista dá forma às relações de poder que nos ligam uns aos outros, mas essas relações também repetem relações de poder antigas, de modo que a repetição é inconscientemente dirigida, e então reaparece na clínica como aquilo que os psicanalistas chamam de "transferência". É através dessas questões que a psicanálise agarra a natureza dos sintomas enquanto indicações de angústia nessa sociedade.

Os sintomas têm sido criados de tal maneira que a psicanálise, uma invenção histórica, é equipada para os ler, e ela nos ajuda a ver o que eles realmente são, como conflitos numa vida pessoal e como expressando conflitos sociais. Uma sociedade 
específica e uma pessoa singular nessa sociedade são o que manifesta seus problemas de maneira sintomática. Os sintomas são indicadores de que alguma coisa está errada, e comunica como o sofrimento está aparecendo em cada sujeito.

Nós nos referimos a seres humanos como "sujeitos" aqui porque o termo "indivíduo" é uma redução muito grande, e sugere que nossa subjetividade é nãodividida e separada, isolada, oposta à sociedade e presa na individualidade. Um "sujeito" é mais que o indivíduo, ele inclui outras pessoas, ele é aberto ao e atravessado pelo mundo social, habitado e dividido pelo lado de fora. O sujeito está em contradição consigo mesmo e, por essa razão, ele pode ser a fonte de agência e mudança, seja a nível da pessoa individual ou a nível do processo político coletivo.

O sujeito pode ser um agente histórico, mas também uma vítima e um produto da história. Os eventos nos afetam e nos determinam de modos diferentes, que atualmente podem ser abordados através da psicanálise. O pensamento psicanalítico é um dos recursos mais poderosos disponíveis a nós para entender e mudar nossa experiência em tempos modernos. O que estava acontecendo conosco enquanto sujeitos da alta modernidade, entre os séculos dezenove e vinte, de repente ganhou, com o desenvolvimento da teoria freudiana, um sentido radicalmente novo. Os nomes para nosso sofrimento foram inventados, e ao mesmo tempo a psicanálise foi inventada para lidar com eles, para se rebelar contra o que eles significavam, para transformar essa angústia.

A psicanálise ainda é um dos melhores modos de alcançar a natureza de nossos sintomas atuais da miséria da vida sob o capitalismo neoliberal avançado, com suas formas associadas de sexismo, racismo e colonialismo. Esses sintomas psicanalíticos que operam inconscientemente, e então encontram uma expressão distorcida nos sintomas visíveis que os médicos e os psicólogos observam, têm uma conexão mais profunda com nossas biografias individuais e com nossas condições atuais de vida. Os sintomas são fenômenos históricos desse duplo sentido; eles são produzidos na história pessoal de cada indivíduo e sua forma geral é estruturada pelo tipo de sociedade em que vivemos e que tentamos entender.

Nosso passado e nosso mundo nos assombram, nos fazem doentes e nos fazem sofrer. Isso acontece seja porque somos completamente enfeitiçados pela ideologia e acreditamos que esse é o melhor de todos os mundos possíveis, sem motivos para se 
preocupar, ou porque somos ativistas que sabem que as coisas estão ruins e que têm que mudar. Conflitos e contradições nos atormentam todos, e esses conflitos e contradições vão fundo dentro de nós, se enfiam em nós, nos rasgam e então tomam a forma de sintomas que podem ser dolorosos e aparentemente inexplicáveis.

\section{A PSICANÁLISE É DIALÉTICA, NEM PSICOLOGIA NEM PSIQUIATRIA}

O caminho tortuoso da abordagem psicanalítica foi, juntamente com o desenvolvimento da psicologia, compreendido como uma especialidade científica ou pseudocientífica, e como uma disciplina profissional e acadêmica. Essa psicologia não deve ser confundida com psicanálise. Embora ela tenha frequentemente conseguido a absorver, ela discorda com a psicanálise em suas premissas, ideias, métodos e objetivos. A psicologia, de fato, é constituída por muito daquilo que tentamos resolver através da psicanálise. Do ponto de vista psicanalítico, a esfera psicológica é problemática.

A psicologia ganha corpo, para nós, como uma experiência ilusória, enganosa e até delirante, isto é, a experiência de cada um de nós como um indivíduo não dividido e avulso, que pode se conhecer e controlar totalmente como um objeto. Esse eu unitário é exatamente parte do problema porque ele leva cada pessoa a imaginar que ela eles deveriam se responsabilizar por seus sentimentos desagradáveis não desejados, e os fazem sentir ainda pior caso se sintam "divididos", se eles pressentem que existe uma dimensão inconsciente de suas vidas. Tal divisão, que afeta a todos nós, é reconhecida pela psicanálise e negada pela psicologia. Sua negação oculta nossa alienação e nos impede de resistir contra o que nos aliena. Ela assim contribui para nos dominar "desde o interior", para nos manipular e nos gerir ideologicamente.

Um problema central que enfrentamos agora é a construção histórica de uma experiência individual isolada, que não corresponde a nossa existência, não pode reconhecer a si mesma em nossos sentimentos e pensamentos, não tem nenhum poder ou percepção dentro dela mesma e é, portanto, vulnerável a dominação, manipulação e gerenciamento ideológico. Aqui está o problema da psicologia apartada da natureza coletiva partilhada de nossas vidas como seres humanos. Ele é, na raiz, um 
problema do individualismo na sociedade capitalista e em suas manifestações psicológicas.

\section{Psicologia}

A disciplina da psicologia é devotada à manutenção de cada eu individual enquanto uma esfera psicológica avulsa, enquanto a experiência de suas próprias experiências, como aquela de cada trabalhador isolado dos outros. A psicologia, disciplina acadêmica profissional e a percepção de nossa própria psicologia individual não dividida sobre a qual trabalha a disciplina, foi formada ao mesmo tempo que o próprio capitalismo, e se espalhou, com o capitalismo, ao redor do mundo. A expansão do capital ao redor do mundo foi também a disseminação global desses dispositivos psicológicos, não somente em universidades e instituições de saúde, mas em todas as esferas da vida. Tudo tende a ser colorido com um tom psicológico. Esse processo de psicologização envolve mecanismos de atomização, dessocialização, despolitização, des-historicização, patologização, criminalização de indivíduos e adaptação à sociedade capitalista.

Sim, nós vivemos sob um capitalismo global, sob um capitalismo neoliberal brutal hoje, mas para entender como esse capitalismo funciona, nós precisamos alguma coisa mais do que simplesmente um nome para o problema. A psicanálise, e não somente a psicanálise, nos ensina que é impossível falar da vida sob o capitalismo, falar de classe, sem também falar de sexismo e racismo, e diversas outras formas de opressão que incapacitam pessoas. A psicanálise radical já é "interseccional", endereçando a profunda ligação subjetiva entre as diferentes formas de opressão que os diferentes movimentos de libertação surgiram para combater e colocar um fim.

Libertar-nos das experiências opressivas de classe, raça e sexo requer combatêlas "dentro" de nós mesmos também. Aqui, na esfera subjetiva, o que é oprimido aparece não somente como afetado, mas também como resignado ou adaptado à opressão. Essa adaptação, que sustenta e perpetua o que nos oprime, é frequentemente vista como "saúde mental" por psicólogos e psiquiatras.

Intimamente ligado a um modelo psiquiátrico de sofrimento, ela se desenvolveu mundialmente como uma ferramenta psicoterapêutica para adaptar 
pessoas à realidade ao invés de permiti-las mudá-la. A psicologia aproveita a maior parte da bagagem histórica ideológica da psiquiatria médica e diz humanizá-la, focando nos sintomas mensuráveis por observação no comportamento de seus clientes, ao invés dos sintomas de doenças mentais invisíveis. Essa mudança da doença para o comportamento não é exatamente um passo à frente, e a psicanálise mostra as limitações dessa mudança mínima de foco. A psicanálise não é psiquiatria. Mas o legado médico ainda está presente dentro da psicologia, mesmo quando os psicólogos se apresentam mais amigáveis, progressistas e "psicoterapêuticos". Nós devemos ser claros aqui de que há diferenças teóricas importantes, assim como embates por status profissional, entre psiquiatras que são treinados de forma médica, psicólogos que têm seus próprios modelos reduzidos de comportamento e pensamento individuais, e psicoterapeutas que misturam e combinam qualquer abordagem que parecer funcionar melhor para acalmar o sofrimento e encaixar as pessoas de volta no mundo.

No momento, são os psicólogos que estão no palco central com suas reivindicações de expertise científica. Eles se consideram os mais efetivos, e comparam sua efetividade com aquilo que é atribuído à psiquiatria, à psicoterapia, e à clínica psicanalítica. Seria mais fácil para nossa tarefa - argumentar em favor do valor da psicanálise - se a psicologia não funcionasse. O problema é precisamente que ela funciona; a psicologia vai muito bem com relações sociais exploradoras e opressivas, e funciona muito bem na adaptação de pessoas, para que elas façam com que esse tipo de mundo continue funcionando de maneira minimamente suave. Ele funciona suavemente até que existam sintomas, com os quais ele então usa suas habilidades supostamente psicoterapêuticas para amenizar.

A propagação da psicologia ao redor do mundo e em nossa vida cotidiana está produzindo uma redução, contração e simplificação da experiência, do modo como sentimos, pensamos e falamos sobre nós mesmos. Nosso comportamento é mais e mais parecido àquele das caricaturas psicológicas simplistas da existência humana que nos cercam por todos os lados. Essas caricaturas são disseminadas por meios como filmes e televisão, revistas e jornais, bestsellers e manuais de autoajuda, educação, psicoterapia, coaching, opiniões de especialistas, redes sociais e até mesmo igrejas pentecostais. Todo o ambiente cultural está saturado com representações psicológicas banais, altamente funcionais para o sistema capitalista, em que nós certamente nos 
reconhecemos. Reconhecemos a nós mesmos nelas, não porque elas são tão fiéis que refletem aquilo que realmente poderíamos ser, mas porque são tão poderosas que nos fazem refleti-las naquilo que somos no momento, nessas condições miseráveis de vida.

A psicologia tem tanto sucesso porque consegue se desdobrar através de nossa existência, confirmando-a como ela é agora. Às vezes, essa existência parece materializar conceitos das grandes tradições psicológicas, incluindo essas dos behavioristas, humanistas e os mestres disciplinares cognitivos. Os consumidores aprenderam, por exemplo, a responder a estímulos de propaganda, a se identificar com a imagem de natureza humana que é vendida a eles, a processar a informação necessária para comprar e se render aos impulsos escondidos que os empurram ao consumismo enquanto ideologia e prática material.

Existem até versões psicanalíticas bem-sucedidas da psicologia, assim como há versões psicanalíticas da psiquiatria. Precisamos estar atentos sobre esses impostores, essas distorções ideológicas e capitulações daquilo que pode ser uma abordagem radicalmente libertadora. A psicanálise não se pode tornar psiquiatria ou psicologia sem deixar de ser o que é, perdendo sua utilidade para movimentos de libertação e até se tornando nociva a eles, não somente despolitizando ao psicologizar ou psiquiatrizar, mas contribuindo para adaptar e subjugar, ao invés de libertar.

É possível adulterar e degradar a psicanálise ao fazê-la funcionar como psicologia, e ajudar sujeitos a serem o que eles deveriam ser para inseri-los da maneira mais eficiente no capitalismo. Contudo, se queremos preservar a psicanálise para aquilo que ela realmente é e pode ser, precisamos separá-la desse processo, e mostrar como a psicanálise pode nos capacitar a resistir a isso. A psicanálise, ela mesma, por causa da história de adaptação à qual ela foi sujeita, se tornou implicada com a ideologia, mas ela se rebela. É como se a psicanálise fosse um sintoma da opressão que agora pode ser usado para falar, e que no processo de falar bem da psicanálise nós podemos libertá-la e libertar a nós mesmos.

A psicanálise é rasgada por conflitos, e ela fala de conflitos em sua abordagem da nossa natureza humana historicamente construída. Ela emergiu num momento histórico preciso, refletindo necessidades, inclinações, desejos e aspirações contraditórios ao tipo de sujeito humano que carrega as contradições de uma certa 
sociedade em suas próprias profundezas, e é por isso que podemos também falar da psicanálise, ela mesma, enquanto um sintoma.

A abordagem psicanalítica não somente lida com manifestações sintomáticas do sofrimento do sujeito, mas é, ela mesma, um sintoma. Ela é tão contraditória quanto aquilo a que se endereça. No mesmo momento em que demandamos da psicanálise que ela trate a natureza contraditória da vida sob o capitalismo, trate os sintomas que surgem hoje nessa sociedade, nós também demandamos que ela deva ser uma "psicologia crítica" reflexiva capaz de examinar a si mesma; nós devemos analisar o que faz a psicanálise se adaptar à sociedade e o que a faz resistir e se tornar algo subversivo e libertador.

\section{Conflito}

Da mesma forma como acontece com a psicanálise, acontece com cada indivíduo que carrega um sintoma dentro de si. Os indivíduos são rotineiramente pegos em relações opressivas nocivas por um padrão específico de experiências diferenciadas biograficamente, e é isso o que vem a definir quem eles são. É isso que os faz reconhecíveis enquanto a mesma pessoa a si mesmos, suas famílias e amigos.

O que é distintivo sobre cada um de nós é uma coisa inconsciente na qual estamos presos, algo resistente e repetitivo, assim como contraditório, conflitivo. Há um conflito interno que ganha corpo no sintoma peculiar a cada um de nós. Esse sintoma pode nos paralisar e impedir-nos de transformar a nós mesmos e de modificar as relações que nos oprimem e machucam. A mudança frequentemente acontece quando algo dramático ou traumático acontece conosco, ela nos separa desses

padrões inconscientemente dirigidos, e a mudança social é um grande fator na cutucada para a mudança individual.

O processo de mudança e a cristalização do conflito no sintoma podem ser compreendidos dialeticamente. O conflito é o que nos prende, o que nos imobiliza, mas é, ao mesmo tempo, o que nos faz nos mexermos para resolvê-lo e nos libertar dele. Nosso movimento é tanto impulsionado quanto dificultado pelo conflito. Isso nos faz mover de pouco em pouco, avanço e tropeço, mudando sem mudar quase nada, algo que é particularmente aparente quando há uma série de pequenas mudanças que 
de repente levam a uma transformação, mudanças quantitativas incrementais que preparam o caminho para um giro qualitativo. Isso acontece no nível político quando uma luta coletiva sustentada leva finalmente, após anos de esforço, a novas possibilidades e novas formas de aparecimento de subjetividades. E isso acontece na clínica quando o sintoma se manifesta como um conflito aberto e pede uma decisão sobre como seguir com a vida. O sintoma é um obstáculo, mas também, dialeticamente, é uma oportunidade.

O sintoma é uma oportunidade para mudança, não somente para nos conhecermos. É por isso que o sintoma não deve ser eliminado, como psicólogos e psiquiatras normalmente fazem, assim assegurando que nada é descoberto e que tudo permaneça igual. Para descobrir e transformar a si mesmo, é preciso escutar o sintoma com a maior atenção, como é feito na psicanálise.

Pessoas vêm ao psicanalista não porque têm sintomas, uma vez que todos nessa sociedade doente estão ocupados por sintomas, mas quando esses sintomas se tornam insuportáveis, quando há um giro iminente da miséria quantitativa para algum tipo de mudança qualitativa. Uma das tarefas da psicanálise clínica é dirigir o tratamento de modo que essa mudança qualitativa aconteça na forma de uma oportunidade para reflexão e escolha decidida sobre como viver a vida, ao invés de colapso e desespero. A psicanálise ajuda o sujeito a não ser sobrecarregado ou derrotado por aquilo que é manifestado no sintoma, a superar isso, o que só é possível ao se escutar o sintoma e agir em acordo com isso. O sintoma é dialético por natureza, e a psicanálise é uma abordagem dialética que ajuda o sujeito individual a tomar um novo curso, em direção à adaptação ou à libertação.

Para ser libertadora, a psicanálise precisa ser libertada. Ela precisa ser desprendida daquilo que não é e não deve ser. Ela deve ser purificada do sedimento de mistificações, preconceitos, valores morais malignos, dogmas, estereótipos e ilusões que a fizeram passar de uma abordagem progressista a uma que é instrumentalmente útil ao capitalismo e colonialismo, e a relações opressivas de gênero.

A psicanálise foi instrumentalizada nos sucessivos contextos aos quais tentou se adaptar. Esses contextos a imbuíram com suas normas, crenças, preconceitos e valores, exigindo moderação e compromisso. No decorrer da história, todo tipo de 
conteúdo ideológico reacionário foi injetado em sua forma radical. Esse conteúdo ideológico, que inclui ideias venenosas sobre diferenças subjacentes essenciais entre homens e mulheres e sua sexualidade - e sua relação genderizada um com o outro , está presa no corpo da psicanálise como uma forma de prática, uma prática de fala. Isso é sério porque a psicanálise é, ela mesma, uma "talking cure" [cura pela fala] que nos mostra como o que dizemos está interconectado com o que fazemos.

Os conflitos e contradições de nossa sociedade de classe são inseparáveis de nossa fala, assim como de nossa vida sexual, o que também está no centro da psicanálise. Nós tentaremos explicar, no decorrer deste manifesto, porque isso é assim, como é que a psicanálise se hospedou na sexualidade precisamente porque aquela sexualidade era vista como o cerne íntimo de nossas vidas. Se a família nuclear era experienciada como o coração de um mundo sem coração quando o capitalismo se desenvolveu, a sexualidade foi experienciada como a parte mais privada e secreta de nós mesmos. Mas ela não foi somente "reprimida", coberta como algo vergonhoso e afastada como algo ruim, mas incitada, demandada de nós. Ela foi assim transformada em uma obsessão, assim como em nosso ponto mais fraco, uma ferida aberta, constantemente irritada, que serve para nos dominar em uma lógica "héteropatriarcal".

O patriarcado é sempre "hétero-patriarcado". Ele é sempre heteronormativo, isso é, torna a heterossexualidade compulsória a base do contrato social de nosso mundo globalizado porque isso reforça o poder dos homens sobre as mulheres, e dos homens velhos sobre os homens jovens, e exclui, ou mal tolera, outras formas de sexualidade. Esse é o caso mesmo quando o capitalismo patriarcal usa uma versão distorcida do discurso feminista contra a esquerda, ou transforma variedades de preferência sexual em um nicho de mercado.

Assim como o capitalismo patriarcal pode instrumentalizar o feminismo e a diversidade sexual, ele também pode transformar a psicanálise em seu instrumento para normalizar e explorar nossas vidas sexuais. Nossa sexualidade, portanto, corre o risco de ser condicionada pelo discurso patriarcal não somente no domínio cultural, mas também no setting clínico psicanalítico. Nós podemos purgar a psicanálise desse veneno ideológico agora, permitindo que ela fale por nós, e não contra nós ou ao invés de nós. 
Então, contra a psicologia e a psiquiatria, e a maioria das formas de psicoterapia, a psicanálise é uma profissão psi com uma diferença. Ela sabe como nos escutar e não está condenada a falar em nosso lugar. Portanto, ao invés de fingir colocar as coisas no lugar, ela trata o sintoma de nosso sofrimento como uma mensagem do sujeito sobre sua condição miserável e, crucialmente, sobre a necessidade de mudança. Nesse sentido, ela tem o potencial de ser uma aliada inestimável de movimentos de libertação. Ela é, ela mesma, uma teoria dialética e uma prática de libertação.

\section{LIBERTAÇÃO NA CLÍNICA E NA CULTURA}

A psicanálise tem sido apropriada por aqueles com poder, é verdade, mas isso não significa que devemos deixá-la ir, deixá-la cair nas mãos deles. Nós devemos, ao invés, reapropriar a psicanálise. Para fazer isso, precisamos agarrar a relação dialética entre seu trabalho clínico e seu contexto histórico sempre em mutação. As condições históricas que viram o nascimento da psicanálise, da alienação sob o capitalismo, exploração da vida e a natureza opressiva da família nuclear da Europa ocidental, foram precisamente as condições que a psicanálise visava entender e combater. Era nessas condições que a sexualidade foi experienciada como traumática, porque ela foi reprimida, mas, ao mesmo tempo, falada incessantemente, provocada.

As condições em que a psicanálise apareceu, e as forças ideológicas em ação, entraram na psicanálise, a distorcendo. Não existe uma psicanálise "pura" nãoideológica, mas pode existir uma limpeza permanente de suas elaborações teóricas, purificação permanentemente sem fim de seus conceitos fundamentais. A complexa relação dialética entre sua forma clínica e os aspectos ideológicos da teoria pode ser constantemente clarificada e transcendida na prática. É um processo contínuo, sempre inacabado, de luta contra o poder, crítica da ideologia e resistência contra psicologização.

A psicanálise precisa ser recriada por nós como uma ferramenta de trabalho radical sobre a subjetividade, que é necessário se queremos que aconteça uma derrubada bem-sucedida das condições existentes. Entendida dialeticamente, essa ferramenta é o resultado de elaborações teóricas de Freud e seus seguidores, que nos 
permitiram usá-la para trabalhos radicais na clínica e com movimentos de libertação. 0 que isso produz é parte de um processo criativo que nos permite fazer mais. Nosso nome para o que isso torna possível é "subjetividade revolucionária", um "sujeito revolucionário".

Como na clínica, também acontece na política, o sujeito revolucionário aparece e desaparece, ganha existência, forjado na luta, e desaparece aos poucos quando seu trabalho está feito. Isso tudo não vai nos transformar em indivíduos heroicamente revolucionários, ativistas carismáticos, ou líderes endurecidos pela batalha. O que nos preocupa não é a formação de lideranças ou personalidades, mas a criação de um processo coletivo de mudança que antecipa o tipo de mundo que queremos construir, nada mais que isso.

Isso não vai nos transformar em psicanalistas - longe disso - , e o resultado final que a psicanálise sempre visa é permitir ao sujeito humano chutar a escada que usou para alcançar um lugar novo. A perspectiva psicanalítica não deve cerrar nosso horizonte. Ela é uma oportunidade, não uma armadilha. Ao acabar com o mundo que cria tanta miséria, nós também antecipamos o fim da psicanálise, como uma abordagem revolucionária que está funcionando como uma ferramenta, e um resultado de um processo histórico. 